\title{
Kinematic Analysis of Volleyball Attack in the Net Center with Various Types of Take-Off
}

\author{
by \\ František Zahálka1, Tomáš Malý1 ${ }^{1}$ Lucia Malá ${ }^{1}$, Miloslav Ejem¹, Marek Zawartka²
}

The aim of the study was to describe and compare kinematics in two types of execution of attack hit, the goofy approach and regular approach. The research group consisted of players from the Czech Republic's top league $(n=12$, age $28.0 \pm 4.3$ years, body height $196.6 \pm 5.6 \mathrm{~cm}$, body mass $89.7 \pm 6.7 \mathrm{~kg}$ ) divided into two groups according to the individual type of approach in the attack. Analysis of movement was performed by $3 D$ kinematics video analysis, space coordinates were calculated by the DLT (Direct Linear Transformation) method together with interpretation software TEMA Bio 2.3 (Image Systems AB, Sweden). The players started their run-up from a distance of about $4-4.5 \mathrm{~m}$ from the net with similar maximal vertical velocity $\left(2.91-2.96 \mathrm{~m} \cdot \mathrm{s}^{-1}\right)$. The trajectory of players with goofy approach seemed to be convenient for the rotation of shoulders and hips in the moment of ball contact. Differences between both groups were observed. Players with a goofy approach had a longer flight phase compared to regularly approaching players.

Key words: 3D analysis, spike, goofy approach, elite athletes.

\section{Introduction}

Volleyball is one of the most popular team sports games in the world. Pass, set up, attack, block, etc., can be mentioned as examples of individual basic skills creating the game. All of them utilize various motor skills and abilities as jumps, swings or different ways of locomotion as well as power, agility, flexibility and speed of reaction (Lehnert et al., 2017). Elite players are requested to possess a high level of the above mentioned skills and abilities; among them jumping ability that influences performance in some of volleyball's basic skills. As Coleman et al. (1993) stated, in order to reach success in volleyball it is necessary to possess strong and efficient offensive skills. The individual attack is currently the main form of team's offense in modern volleyball. This is why numerous scientific studies attempt to investigate this basic skill from various points of view. Tillman et al. (2004) and Kugler et al. (1996) indicate that elite attackers training about $16-20$ hours a week, perform approximately 40000 attacks (and therefore also jumps) in a year.

Comprehensive kinematic analysis of the attack hit, utilizing observations of inverse dynamic variables, was described by Wagner et al. (2009). In that study, they tried to find differences between the Counter Movement Jump (CMJ) and Spike Jump (SJ). Forthomme et al. (2009) presented factors correlated with the speed of the attack hit. Tilp et al. (2008) described biomechanical differences in the attack hit performed by indoor and beach volleyball players. Efficiency of various methods for improvement of jump's height while hitting was also investigated by Newton et al. (1999), Reeberg et al. (2008), Sheppard et al. (2008), Sheppard et al. (2009) and others. Some studies also deal with landing after an attack hit; they however concentrate on health and injury prevention

\footnotetext{
1 - Faculty of Physical Education and Sports, Sports Research Centre, Charles University, Prague, Czech Republic

2 - Faculty of Internal Security, J. Kukuczka Academy of Physical Education in Katowice.Katowice, Poland
} 
(Bisseling et al., 2008; Cronin et al., 2008; Marquez et al., 2009; Tillman et al., 2004). Most of the studies are conducted by utilization of the attack hit from outside court zones IV and II. However, elite volleyball players display very good blocking skills, mainly by creating double or triple blocks. To overcome strong net defense, the attacking teams use quick attacks at the net center with the aim to tie the opponent's middle blocker to their own middle attacker and thus, not to allow defenders to mount a solid multiple block. Should the middle blockers act successfully against such an imminent danger, they must commit themselves to the opponent's attacker what in turn makes them late for multiple blocking outside. This is why the middle quick hitting is so imperative for efficient attack (McGown et al., 2001). Quick hitting in the net center follows regularly sets of the first tempo, mostly those called one, two, three and slide in the well-known book of McGown et al. (2001). All these first tempo hits require attackers to time the approach according to the pass or serve reception and not as late as according to the set released from the fingertips of a setter.

From the kinematic point of view, the entire movement of the attack hit may be divided into three main phases: approach, take-off and arm swing with the hit itself. Beside the mentioned phases the authors selected a few critical points in the entire movement cycle. Focusing on them served for more precise comparisons of respective attempts and will be named later on. The approach usually consists of 3-4 steps. Right-handers end the so called one-two approach most often by a long braking step from the left to right leg followed by a "staggered hop" by the left leg (McGown et al., 2001). Lefthanders perform the same reciprocally. In current volleyball it is however possible to meet players using the opposite sequence of steps before takeoff, well known as the "goofy" approach. To assume such a take-off posture, the players must adjust their approach accordingly. This variation of approach is a kind of a remnant from the time when the last breaking step to take-off posture was recommended to finish by landing on both feet shoulder width together and parallel. The working hypothesis therefore considers that both executions of the attack hit may differ not only in awaited distinct step sequences, but in many other movement features, namely in positioning of the hitter in regard to a setter, in diverse directions and approach paths as well as in contrasting biomechanical variables. There may also be other factors influencing hitting performance. Detailed analysis of these two approach variations may bring not only precise description of their differences, but consequently also important knowledge supporting and justifying the decision whether and/or when players relearn their way of attack approach or when to respect their individual way of execution.

\section{Methods}

\section{Participants}

The research sample consisted of players from the men's top league in the Czech Republic $(\mathrm{n}=12$, age $28.0 \pm 4.3$ years, body height $196.6 \pm$ $5.6 \mathrm{~cm}$, body mass $89.7 \pm 6.7 \mathrm{~kg}$ ) with very stable spike technique; the players were divided into the goofy approach (GA) group ( $n=6$, age $=32.3 \pm 2.2$ years, body height $197.7 \pm 1.5 \mathrm{~cm}$, body mass 91.7 $\pm 4.6 \mathrm{~kg})$ and regular approach (RA) group $(\mathrm{n}=6$, age $=24.8$ years, body height $195.5 \pm 7.6 \mathrm{~cm}$, body mass $87.8 \pm 7.92 \mathrm{~kg}$ ).

\section{Procedures}

Recording of movement kinematics was performed in the game situation. The analyzed hitter commenced the movement in the center of the court, approximately $4 \mathrm{~m}$ off the net. To keep the model situation as standard as possible, a specially selected and technically stable player stood close, and to the right of the tested subject to start the experimental trial by passing the ball. This player passed the ball overhead to the setter, who passed the ball to a hitter. Following the pass, the hitter performed the attack after the set No. 54 (often used American notation). A setter was placed in the regular position of a penetrating setter, i.e. close to the net on the boundary of zones II and III. The setter tried to repeat exactly the same sets to all participating players. All players performed three hit attempts with a $1 \mathrm{~min}$ rest period in between.

The observation took place during the afternoon practice after a standard warm-up of 20 min. Gala Pro-line BV 5591 S balls were used throughout the entire experiment. The hits were recorded by three static SONY HDR-HC9E (SONY CORPORATION ${ }^{\circledR}$, Japan) video cameras with the interlaced rate of $50 \mathrm{fps}$. The recorded 
space was calibrated by block $4 \times 1 \times 2 \mathrm{~m}$ with 16 calibration points. Space coordinates were calculated by the help of the DLT (Direct Linear Transformation) method together with interpretation software TEMA Bio 2.3 (Image Systems AB, Sweden). The recorded space covered the court up to the distance of $5 \mathrm{~m}$ from the net and reconstruction error was calculated as $0.025 \mathrm{~m}$ what is equal to $0.5 \%$ of the recorded space size. Also 16 reference points (right and left foot's tip, right ankle, right and left hip, right and left shoulder, right and left elbow, right and left wrist, and head represented by forehead and chins) were marked on the body of each observed athlete. The body's center of gravity (COG) was calculated upon the constructed wire-frame model.

As mentioned above the following critical points of the center net's hit were selected:

Initial posture (body posture at the outset of approach)

Longest step (the longest distance between both feet during the attack)

Last approach's step (the second step in the one-two approach)

Ball's hand contact (the hit itself)

Landing (contact of both feet with the surface)

\section{Results}

The players from both groups (GA and RA) used the 3-step approach (Figure 1). Regularly approaching hitters started movement by the left (goofy by right) leg in the direction of the net (Figure 1). The players started from a position in which their knees were slightly bent and body weight was spread on both legs. The place of the starting position was individually selected by each player, and the starting position of the RA group was $4.5 \pm 0.11 \mathrm{~m}$ from the net $(1.5$ $\mathrm{m}$ from the attack line) while of the GA group, it was $4 \pm 0.15 \mathrm{~m}$ from the net $(1 \mathrm{~m}$ before the attack line). The lateral position of players towards the center of the court was similar in both groups, however the COG was on average $0.3 \mathrm{~m}$ more left from the player's point of view in the RA group.

The COG of participants showed 8 crucial points, specific to COG acceleration changes (Figure 2). According to the time distribution from time 0 to time $1000 \mathrm{~ms}$ (Figure 2), the GA and RA groups kept a similar pattern in acceleration during the first two steps, then, however, their courses started to significantly differ due to an understandable cause. From 1000 ms significant differences occurred. The RA group had the longer last step, in which the midfoot striked well in front of the braking right foot causing the hitter's body to move forward. The take-off position of the feet was similar for both groups with ascending horizontal velocity at 1000 $\mathrm{ms}$ and its hyperbolic course that finished approximately at the time instant of $1700 \mathrm{~ms}$. Between group difference in the horizontal component of velocity was observed upon landing. The GA group had a parallel and simultaneous heel strike of both feet on the surface with short ascending of horizontal speed between $1700-1800 \mathrm{~ms}$. The vertical velocity of both approaches was similar especially in the time of the first peak

Another variable used to compare both types of approach was the length of respective steps. They are illustrated on the "cine-freeze frames" shown in Figure 3. The figure shows that lengths of the first and third steps of the RA players are comparable, and that the second one (braking) is the longest. When approaching using the goofy way, the second step is also longest, however, in contrast to the RA group, the third step of the GA players is similar to the first and extremely short. It resembles run up steps followed by a simple hop and planted take-off. Total distance covered by players in both types of approach is less than $3 \mathrm{~m}$. In spite of the fact, that players move forward, they also displace sideways - for about $0.25 \mathrm{~m}$ to the left (facing the net). It is caused by the last step performed to the left together with body rotation to the right i.e. to the setter. In the time interval of $t=920-1200 \mathrm{~ms}$, the forward velocity of the head drops from its maximal value of approximately $3.5 \mathrm{~m} \cdot \mathrm{s}^{-1}$ to the local minimum of $1 \mathrm{~m} \cdot \mathrm{s}^{-1}$ (difference $2.5 \mathrm{~m} \cdot \mathrm{s}^{-1}$ ). On the other hand, the vertical component of velocity increases from its local minimum of $0.8 \mathrm{~m} \cdot \mathrm{s}^{-1}$ to the maximal value of $3 \mathrm{~m} \cdot \mathrm{s}^{-1}$ (difference $3.8 \mathrm{~m} \cdot \mathrm{s}^{-1}$ ).

Figure 3 illustrates changes of the COG vertical position in the entire movement (right upper graph) together with the changes of entire body speed. Since the outset of the movement, the COG descends for about $0.25 \mathrm{~m}$ to its lowest position. Afterwards, until the last contact of lower limbs with the surface, it moves up for about $0.5 \mathrm{~m}$, which is the moment where the flight 
phase starts.

Both groups displayed a decrease in horizontal velocity that was accompanied by an increase in vertical velocity in order to reach highest possible vertical jump (Figure 4). The entire speed and its changes are manifested as late as before assuming the final take-off position, when the rotation of hips and shoulders before the jump occurs and induce therefore more significant lateral motion. When comparing horizontal and vertical components of a player's body velocity in the GA and RA groups, a sharp decrease of the horizontal component may be observed and similarly, a sharp increase of the vertical velocity component since the moment of last steps' feet surface strike. In the upper dead center of body's flight, the vertical component of velocity drops to zero. Speed of the approach is limited by its maximal value, in which a player is able to transfer most of the energy into the vertical leap and stop moving forward after landing in order not to violate rules by uncontrolled forward motion. Respective movement's phases and courses of vertical as well as horizontal velocity are presented in the lower part of Figures 3 and 4 .

In order to efficiently perform the attack hit, the swing of the hitting arm resulting from the rotational motions of the trunk is very important. Movement execution is initiated by an appropriate position of distal parts of lower limbs during their contact with the surface, rotations, then it passes through the hips and trunk to the shoulders and their movement eventually determines the very motion of upper limbs. Locations of hip and shoulder axes as well as their changes in respective phases of players' movement are shown in Figure 5. In a hitter's initial position, the angles between hip and shoulder lines with respect to the net are almost the same in both groups and account for about $150^{\circ}$. Between the first and second steps, the hips line in the RA group reaches its maximum of $171^{\circ}$ (they are almost parallel to the net), but only $158^{\circ}$ in the GA group (Figure 5b). Immediately after the right leg strikes surface the location of hips and shoulders in regard to the net becomes almost identical in the RA group, yet not in the GA group (Figure 5c).

Before landing on both feet, the shoulder angle remains the same $\left(150^{\circ}\right)$ and rotation occurs only in the lower part of the body in the RA group
(Figure 5d). After landing, the player's body rises and reverse rotation of the hips and shoulders begins when the hips after the maximum rotation from the net $\left(125^{\circ}\right)$ turn back and shoulders continue their rotation opposite to the hips. The same angle of hips and shoulders $\left(133^{\circ}\right)$ is achieved in the last contact of feet with the surface (Figure 5e) in the RA group, which happens earlier compared to the GA group. Hips then rotate towards the net and create tension for rotation of the upper part of the body in both groups. Shoulders of RA players turn up to the moment of the maximum backswing of the hitting arm when the shoulder angle is $105^{\circ}$ and hip angle is $157^{\circ}$ (Figure 5f). The shoulder axis after the maximum backswing rotates toward the net, with the strike moment of $137^{\circ}$ in the RA group and $150^{\circ}$ in the GA group. The hip angle in the strike is $157^{\circ}$ in the RA group and $164^{\circ}$ in the GA group (Figure 5g). After the strike, shoulder and hip rotation continues in the movement direction up to landing in the RA group, yet not in the GA group (Figure 5).

Another key moment is the moment of ball contact with a fully elevated arm. In the ideal case, the ball contact is realized in the upper vertex of the body's flight trajectory. In this particular moment the lower extremities elongate the body vertical axis with moderate flexion in the knee joints. The last key point of the entire skill's technique is landing. A player lands first on the left and then the right leg gradually over their tip toes. Landing on the tip toes with light flexion in knees is very important because of the falling body cushion. The entire position of the body shows how a player coped with the flight phase of the attack. Since the moment when a player left the surface, he/she cannot gain any additional energy and must use it economically. The consequences of all motions and corrective movements are reflected in the trunk and limb positions in the course of landing.

The RA group has the length between the right lower limb position for the first step (Figure 6) of $2.54 \pm 0.04 \mathrm{~m}$ and the GA group of $2.78 \pm 0.08 \mathrm{~m}$. The difference of $0.24 \mathrm{~m}$ is not that great and it is similar to the left side difference of $0.30 \mathrm{~m}$ between the left lower positions for the second step $(2.27 \pm 0.03 \mathrm{~m}$ compared to $1.97 \pm 0.04 \mathrm{~m}$, Figure 6). The similarity was in difference of 0.17 $\mathrm{m}$ between the right and left foot position (Figure 
6). The highest difference was in the width between the right and left foot during the take off (Figure 6), where the RA group presented the value of $0.87 \pm 0.3 \mathrm{~m}$ and the GA group of $0.23 \pm$ $0.02 \mathrm{~m}$. The second step is the longest in all players. It shows that while approaching for the attack the relocation from initial to take-off positions is mainly a matter of the last two steps. The next compared variable between the groups was the velocity of body displacement. The first approach step of the players reaches the velocity of approximately $2.55 \mathrm{~m} \cdot \mathrm{s}^{-1}$, which is then kept and increases during the step (Figure 2). Forward (horizontal) velocity drops after the take-off to about $1.71 \mathrm{~m} \cdot \mathrm{s}^{-1}$. The flight phase of both groups was very similar with maximal vertical velocity in the RA group of 2.91 and in the GA group of 2.96 $\mathrm{m} \cdot \mathrm{s}^{-1}$.

\section{Discussion}

Players of both groups manifested a minimum of intraindividual differences in the attack hit's technique execution. Following the comparison of both absolute values in movement's critical points and the course of changes in respective movement's phases, it can be stated that players possess a very stable movement pattern. This corresponds to the findings of Lehnert et al. (2003) who observed similarly high technique stability in the jump hard serve of elite volleyball players. However, kinematics was influenced by players' somatic features, as taller players performed longer steps, what resulted in a different selection of the initial position for approach as well as the take-off position.

The study also showed that even in the reverse type of "goofy" approach, there was no relationship between the jump height and vertical impulse, similarly as in other types of take offs, namely the step close jump and the hop jump (Coutts, 1982; Gutierrez-Davila et al., 2009). The study emphasizes the importance of the vertical impulse increase during the last two steps regardless of the type of approach, which is in accordance with other studies (Liu et al., 2001). With respect to comparable values of the horizontal component in both types of approaches, conclusions about critical impact of vertical speed on the jump height (Liu et al., 2001; Wagner et al., 2009) were confirmed.

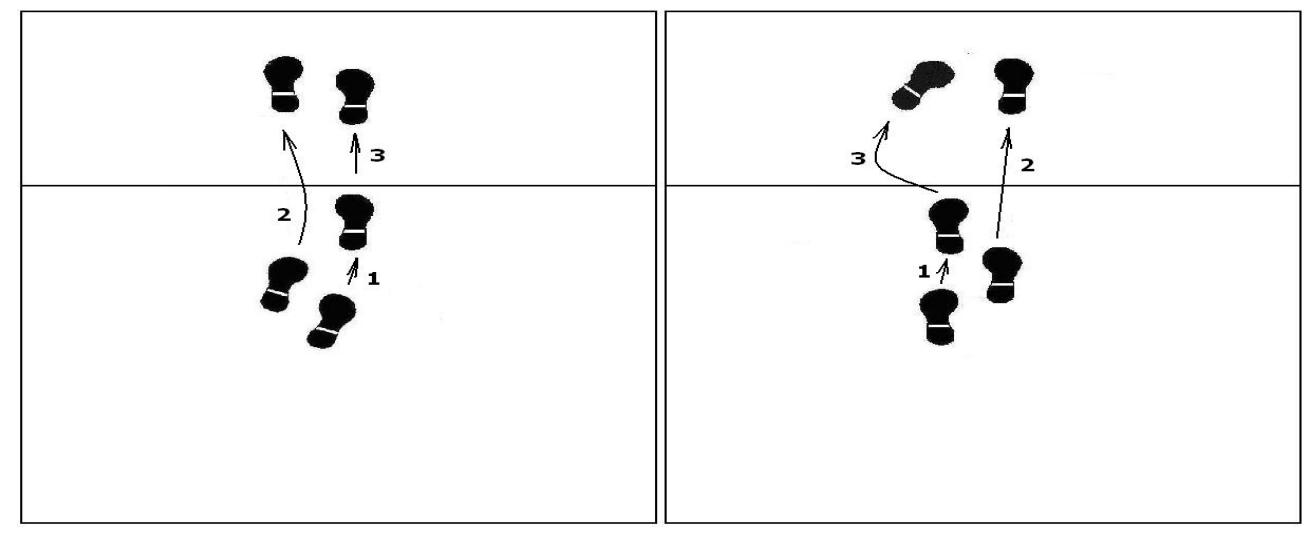

Figure 1

Feet positions in regular and goofy approach 

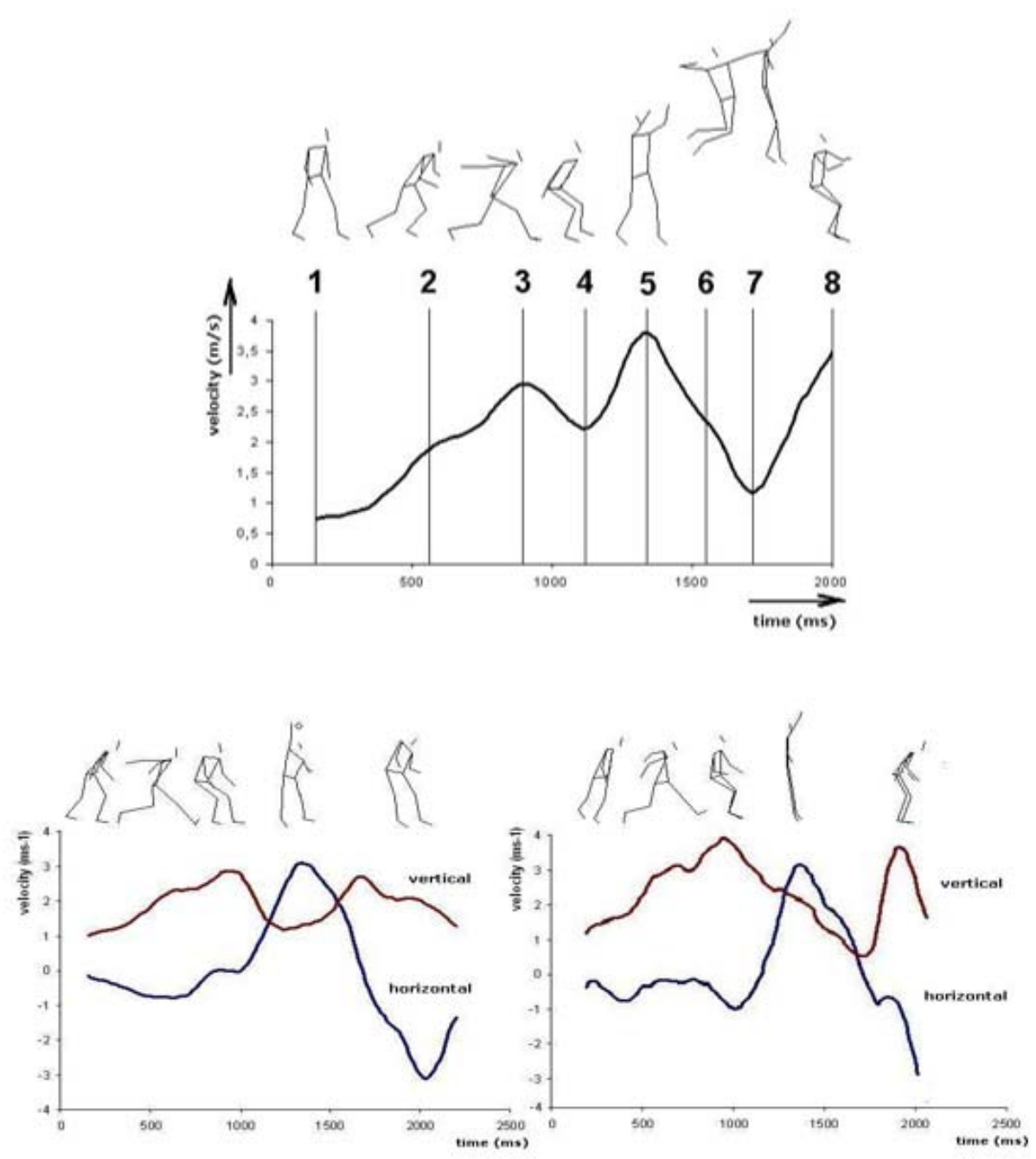

Figure 2

Down left side graph shows regular approach, down right side graph shows goofy approach.

Progression of body center of gravity's speed (calculated as arithmetical mean of regularly approaching players) in the course of the entire movement respective movement phases are drawn in the upper part and comparison of vertical and horizontal velocities of the gravity's center in players with regular and goofy approaches in the lower part

The first two approach steps (No. 1 and No. 2) up to the contact of the right lower limb with the surface - the body's speed represented by the center of gravity accelerates. After the heel strike (instant No. 3) the motion starts to decelerate, but its new acceleration may be observed immediately after lower limbs extension, i. e. the take-off itself (instant No. 4). Leaving the floor and start of the flight phase - (instant No. 5) means a slowdown of the movement again. Motion speed keeps decreasing until the vertex of the flight phase (instant No. 7), then increases again due to the force of gravity. In the moment of landing (instant No. 8) the motion must be stopped totally, mainly because of the rules, in order not to move forward and touch the net. 


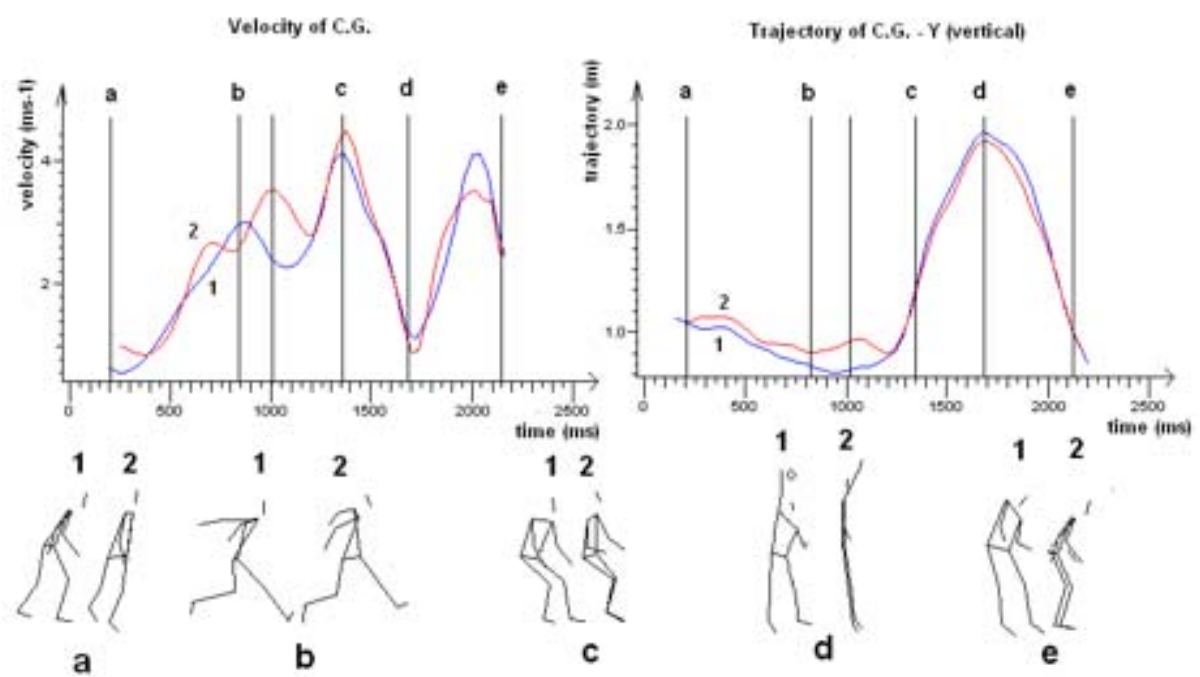

Velocity of the center of gravity movements in all three axes

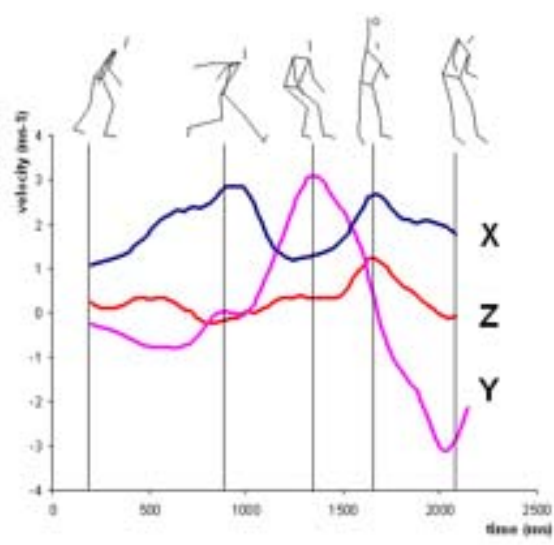

1

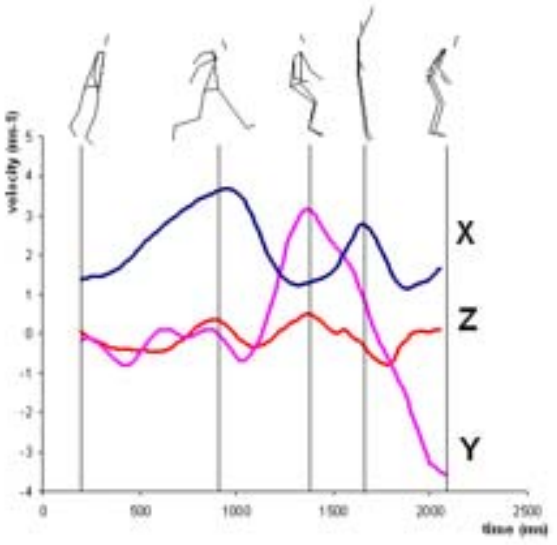

2

Figure 3

Body's center of gravity, velocity and vertical position during two types of approach

1-regular approach, 2-goofy approach

Axis X represents velocity of onward movement in the direction to the net, axis $Y$ velocity of gravity's center vertical displacement (velocity of body's movement up and down) and finally axis $Z$ traces transversal displacement (perpendicularly to the sidelines).

$a$-starting position, $b$-approach, $c$-take off, $d$-the highest position, $e$ landing

Lower part of the picture presents the courses of two velocity components for each observed group of players' centers of gravity, respectively. Red linehorizontal component of velocity - shows the velocity with which players move forward, while the vertical component illustrates the velocity with which players in each particular moment move up or down. 


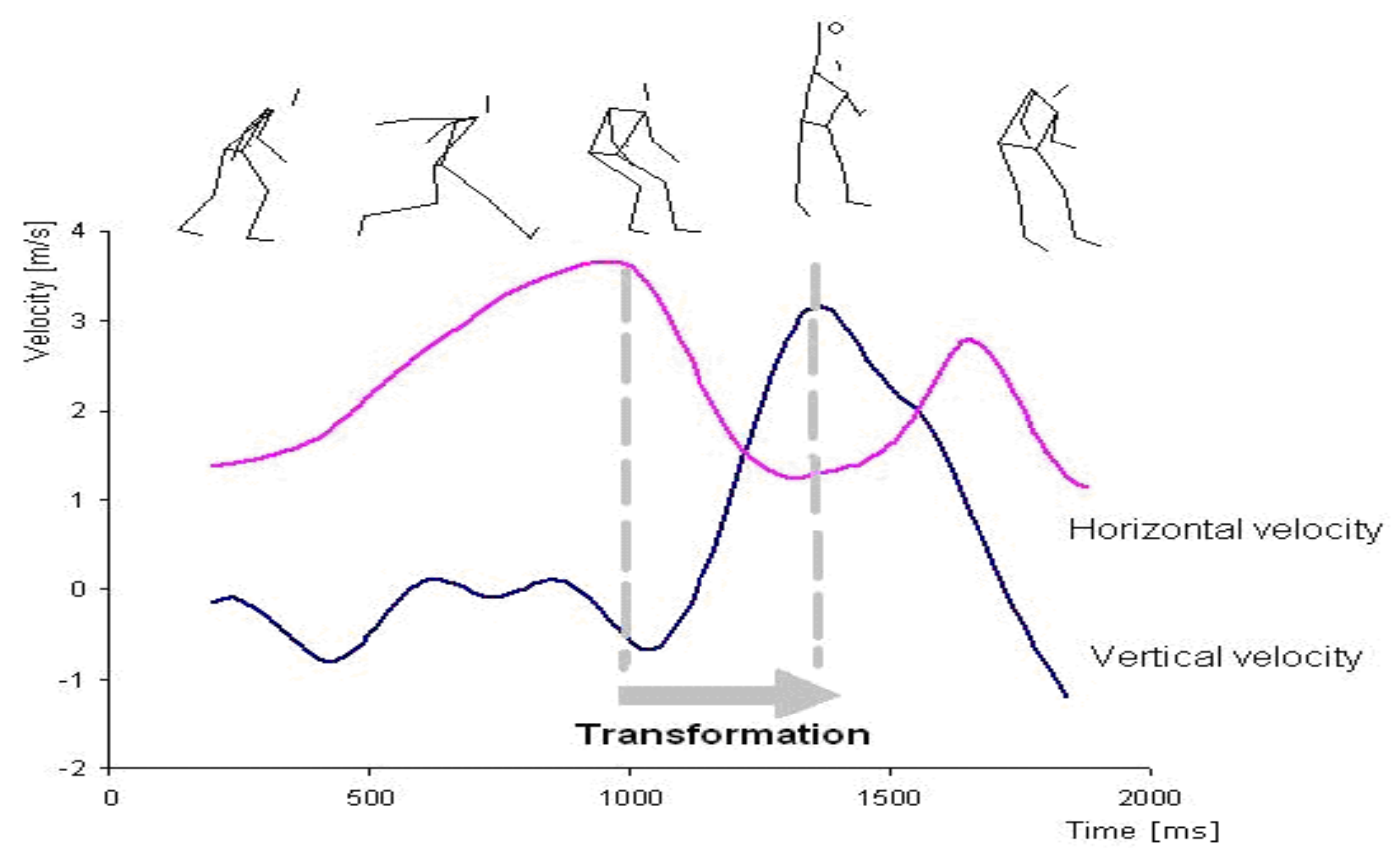

Figure 4

Principle of onward into vertical component velocity transformation Positive and negative values of the velocity's vertical component stand for the upward and downward body motions, respectively; it stands for reason-velocity is only positive, but here the plus and minus signs determine its orientation.
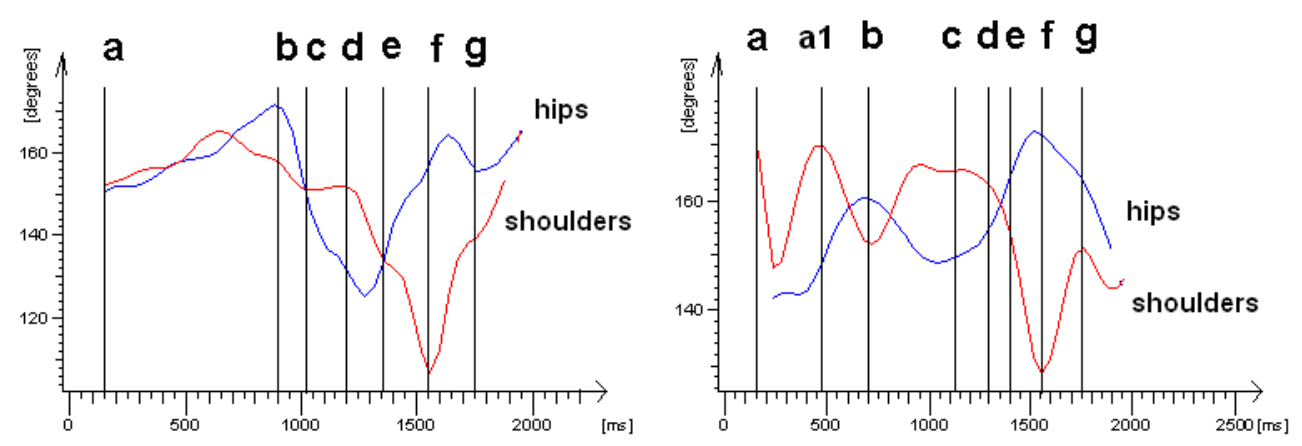

Figure 5

Locations of hip and shoulder axes during both types of the spike left - regular approach, right - goofy approach 

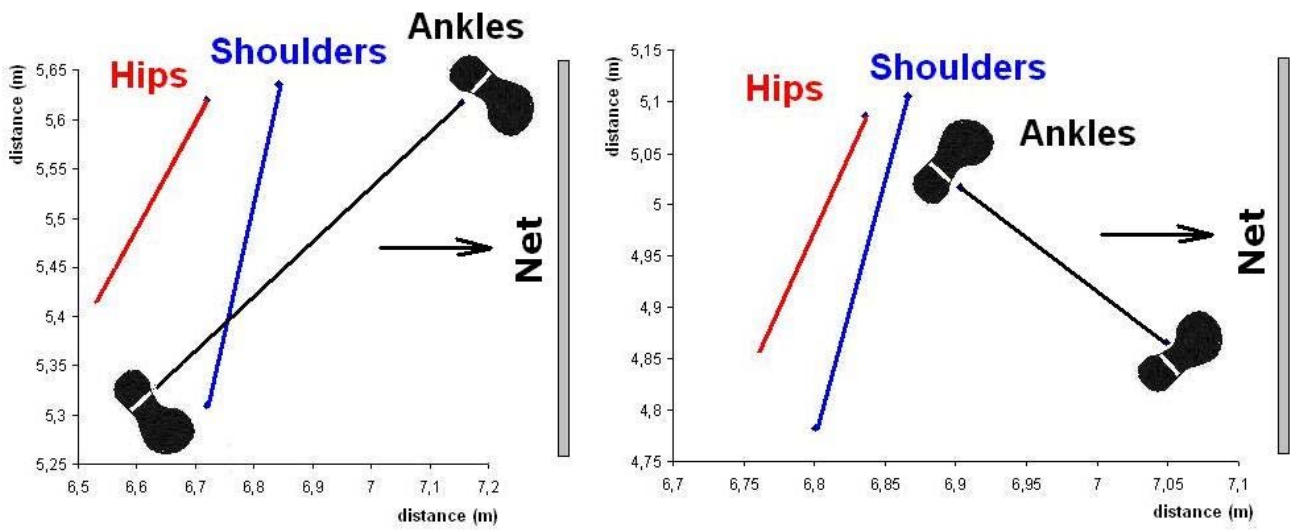

Figure 6

Position of ankles, hips and shoulders as a projection to the ground in the moment of take-off left - regular approach, right - goofy approach

Players with goofy approach usually present a longer flight phase compared to regularly approaching ones. Lowering of the body center of gravity occurs as late as during the last step, which is the beginning of the jump, and this overloads muscles and bones, what may be considered a health risk. As a negative feature, it is also possible to consider the body posture while landing on the surface, as it is more difficult to absorb and cushion body weight when the body still finishes the rotation (Rasmussen and Heneghan, 2001).

Due to the break in vertical velocity's acceleration in the RA group, both variants present practically the same steepness of the upward slope. The similarity between the RA and GA groups can be found in the developing the same final vertical velocity and therefore the same rise of the center of gravity providing the players with enough height to hit well. Also the final course of vertical velocity in both cases coincides and follows the similar descending pattern ending in negative velocity values.
Postures of a torso and lower limbs differ moderately in time variables of lower limb landing and torso's rotation. It coincides closely with the spot in the opponent's court, to which the player placed the ball. Yet this variable was not evaluated in our study and players did not perform their attack against net defense.

It can be stated that players take off with the same velocity and also their landing is very similar from the time point of view. Therefore, the approach is a very important phase for the takeoff. The body COG drops during first two approach's steps and during the third one (after the moment when the foot strikes the ground), when the entire body gradually prepares for the take-off itself.

One of the study limitations lies in the participants' skills level, as this study did not measure whether the players' choice of goofy or regular approach was related to their agility (Hojka et al., 2016) or strength performance (Gołaś et al., 2016); the choice of the type of approach was based on participants' playing habits. 


\section{Conclusions}

Players from both groups possessed high intraindividual stability in attack execution. Similarly, top level players approaching the attack with the same run-up technique possessed high level of interindividual stability in key phases and moments of technique execution. The direction of approach in the group of players using regular technique led more directly to a setter (they covered a shorter distance) compared to players with a goofy approach. These players started their run-up from the distance of about $4-4.5 \mathrm{~m}$ from the net. Yet, the trajectory of players with a goofy approach seemed to be more convenient for the following rotation of shoulders and hips in the moment of ball contact. This phenomenon was the cause of the opposite execution of the step-close and insufficient opening of the body in the direction of a setter. Ending of the last (third) step (by the right leg for the right hand hitter) in the forward direction was a strong predictor of the hit a player would utilize. The last step (step-close) performed by the right leg either aimed more forward (along the $\mathrm{Z}$ axis, i.e. closer to the net) and players thus rather refrained from diagonal hits, or was much shorter signaling thus a diagonal hit (usually a strong way of player's attack execution). Having in mind the aforementioned results, it is possible to claim that the regular approach is more advantageous considering higher variability of initial position's selection, more efficient transfer of the horizontal into vertical impulses and also a better flight trajectory enabling to assume a better position in the air to perform the attack. Another advantage is created by a wider range of possibilities for attack placement, meaning a more difficult situation for opponents' defense. In spite of all these arguments, players with a goofy approach still may be found in top level teams, although it is not too frequent and more often concerns women's volleyball. In future research, it would be necessary to consider whether it is suitable to re-teach the goofy approach in elite players. Practice shows that this issue is not unambiguous as it is possible to find examples of positive as well as negative outcomes of such coaching decisions and it is therefore upon a coach and a player to decide. Future research should also consider a larger sample size and including female volleyball players.

\section{Acknowledgements}

Programme for the Development of Fields of Study at Charles University under Grant Q41, and GAČR 16-21791S.

\section{References}

Bisseling RW, Hof AL, Bredeweg, SW, Zwerver J, Mulder T. Are the take-off and landing phase Dynamics of the volleyball spike jump related to patellar tendinopathy? Brit J Sport Med, 2008; 42(6): 483

Coleman SGG, Benham AS, Northcott SR. A three-dimensional cinematographical analysis of the volleyball spike. J Sport Sci, 1993; 11: 295-302

Coutts KD. Kinetic differences of two volleyball jumping techniques. Med Sci Sport Exer, 1982; 14: 57-59

Cronin JB, Bressel E, Finn L. Augmented Feedback Reduces Ground Reaction Forces in the Landing Phase of the Volleyball Spike Jump. J Sport Rehabil, 2008; 17: 148-159

Dapena J, Chung CS. Vertical and radial motions of the body during the take-off phase of high jumping. Med Sci Sport Exer, 1988; 20(3): 290-302

Forthomme B, Croiser JL, Cicerone G, Crielaard JM, Cloes M. Factors correlated with volleyball spike velocity. Am Sport Med, 2009; 33(10): 1513-1519

Gołaś A, Maszczyk A, Zajac A, Mikołajec K, Stastny P. Optimizing post activation potentiation for explosive activities in competitive sports. J Hum Kinet, 2016; 52(1): 95-106

GutiErrez-Davila M, Campos J, Navarro E. A comparison of two landing styles in a twofoot vertical jump. J 
Strength Cond Res, 2009; 23(1): 325-331

Hojka V, Stastny P, Rehak T, Gołas A, Mostowik A, Zawart M, Musálek M. A systematic review of the main factors that determine agility in sport using structural equation modelling. J Hum Kinet, 2016; 52(1): $115-123$

Kugler A, Krüger-Franke M, Reininger S, Trouillier H, Rosemeyer B. Muscular imbalance and shoulder pain in volleyball attackers. Brit J Sport Med, 1996; 30: 256-259

Lehnert M, Janura M, Stromsik P. The jump serve of the best servers on the Czech national men's volleyball team. Int J Volleyb Res, 2003; 6(1): 10-13

Lehnert M, Sigmund M, Lipinska P, Varekova R, Hroch M, Xaverova Z, Stastny P, Hap P, Zmijewski P. Training-induced changes in physical performance can be achieved without body mass reduction after eight week of strength and injury prevention oriented programme in volleyball female players. Biol Sport, 2017; 34(2): 205-213

Liu GC, Huang GC, Huang C. Effects of different approach lengths of the last stride on volleyballer run up vertical jumps. Proceedings of Oral Sessions: XIX International Symposium on Biomechanics in Sports. San Francisco, CA: University of San Francisco; 2001

Marquez WQ, Masumura M, Ae M. The effects of jumping distance on the landing mechanics after volleyball spike. Sports Biomech, 2009; 8(2): 154-166

Mc Gown C, Fronske H, Moser L. Coaching Volleyball - Building a Winning Team. Needham Heights: Allyn \& Baker; 2001

Newton RU, Kraemer WJ, Häkkinen K. Effects of ballistic training on preseason preparation of elite volleyball players. Med Sci Sport Exer, 1999; 31(2): 323-330

Rasmussen M, Heneghan JM. Sources of error in determining countermovement jump height with the impulse. J Appl Biomech, 2001; 17: 43-54

Reeberg LC, Dourado AC, Oncken P, Mancas S, Da Costa SC. Adaptations on jump capacity in Brazilian volleyball players prior to the under-19 World Championship. J Strength Cond Res, 2008; 22(3): 741749

Sheppard JM, Chapman DW, Gough C, McGuigan MR, Newton RU. Twelve-Month training-induced changes in elite international volleyball players. J Strength Cond Res, 2009; 23(7): 2096-2101

Sheppard JM, Newton RU, McGuigan MR. The effect of depth-jumping on vertical jump performance of elite volleyball players: An examination of the transfer of increased stretch-load tolerance to spike jump performance. JASC, 2008; 16(4): 3-11

Tillman MD, Haas CJ, Brunt D, Bennett GR. Jumping and landing techniques in elite women's volleyball. J Sports Sci Med, 2004; 3: 30-36

Tilp M, Wagner H, Miller E. Difference in 3D kinematics between volleyball and beach volleyball spike movements. Sports Biomech, 2008; 7(3): 386-397

Vint PF, Hinrichs RN. Differences between one-foot and two-foot vertical jump performances. J Appl Biomech, 1996; 12(3): 338-358

Wagner H, Tilp M, von Duvillard SP, Mueller E. Kinematic Analysis of Volleyball Spike Jump. Int J Sports Med, 2009; 30(10): 760-766

\section{Corresponding author:}

\section{František Zahálka}

Charles University, Faculty of Physical Education and Sports,

Sports Research Centre, J.Martiho 31, Prague 6, Czech Republic

Phone: +420220172297

Fax: +420220172288

E-mail: zahalka@ftvs.cuni.cz 